Published in final edited form as:

Int J Radiat Oncol Biol Phys. 2007 December 1; 69(5): 1534-1543.

\title{
Targeted therapy against VEGFR and EGFR with ZD6474 enhances the therapeutic efficacy of irradiation in an orthotopic model of human non-small cell lung cancer
}

\author{
Keiko Shibuya, MD ${ }^{1,2}$, Ritsuko Komaki, MD², Tomoaki Shintani, DDS, PhD ${ }^{2}$, Satoshi Itasaka, \\ $\mathrm{MD}^{2}$, Anderson Ryan, $\mathrm{PhD}^{5}$, Juliane $\mathrm{M}$. Jürgensmeier, $\mathrm{PhD}^{5}$, Luka Milas, $\mathbf{M D}, \mathrm{PhD}^{2}$, Kian \\ Ang, MD, PhD ${ }^{1}$, Roy S. Herbst, MD, PhD ${ }^{3,4}$, and Michael S. O'Reilly, MD ${ }^{1,4}$ \\ 1 Department of Radiation Oncology, MD Anderson Cancer, Houston, Texas \\ 2Department of Experimental Radiation Oncology, MD Anderson Cancer, Houston, Texas \\ 3Department of Thoracic/Head and Neck Medical Oncology, MD Anderson Cancer, Houston, Texas \\ 4Department of Cancer Biology, MD Anderson Cancer, Houston, Texas \\ 5AstraZeneca, Macclesfield, UK
}

\begin{abstract}
Purpose-Conventional therapies for lung cancer have reached a therapeutic plateau. We therefore evaluated the feasibility of combined VEGFR2 and EGFR targeting with radiation therapy in an orthotopic model that closely recapitulates the clinical presentation of human lung cancer.
\end{abstract}

Methods and Materials-The effects of irradiation and/or ZD6474, a small molecule inhibitor of VEGFR2 and EGFR tyrosine kinases, were studied in vitro for human lung adenocarcinoma cells using proliferation and clonogenic assays. The feasibility of combining ZD6474 with radiation therapy was then evaluated in an orthotopic model of human lung adenocarcinoma. Lung tumor burden and spread within the thorax were assessed and tumor and adjacent tissues were analyzed by immunohistochemical staining for multiple parameters including CD31, VEGF, VEGFR2, EGF, EGFR, MMP2, MMP9 and bFGF.

Results-ZD6474 enhanced the radioresponse of NCI-H441 human lung adenocarcinoma cells by a factor of 1.37 and markedly inhibited sublethal damage repair. In vivo, the combined blockade of VEGFR2 and EGFR by ZD6474 blocked pleural effusion formation and angiogenesis and enhanced the anti-vascular and anti-tumor effects of radiation therapy in the orthotopic human lung cancer model and was superior to chemoradiotherapy.

Conclusions-When radiation therapy is combined with VEGFR2 and EGFR blockade a significant enhancement of antiangiogenic, anti-vascular and anti-tumor effects are seen in an orthotopic model of lung cancer. These data provide support for clinical trials of biologically targeted and conventional therapies for human lung cancer.

Corresponding author: Michael S. O'Reilly, MD Anderson Cancer Center, 1515 Holcombe Boulevard, Houston, TX 77030 Phone: 713-563-2300; Fax: 713-563-2331; moreilly@mdanderson.org.

Conflicts of Interest Notification: There are no actual or potential conflicts of interest related to this manuscript.

Publisher's Disclaimer: This is a PDF file of an unedited manuscript that has been accepted for publication. As a service to our customers we are providing this early version of the manuscript. The manuscript will undergo copyediting, typesetting, and review of the resulting proof before it is published in its final citable form. Please note that during the production process errors may be discovered which could affect the content, and all legal disclaimers that apply to the journal pertain. 


\section{Keywords}

Angiogenesis; Lung cancer; Antiangiogenesis; Radiotherapy; Targeted therapy

\section{INTRODUCTION}

Lung cancer is a major health problem worldwide and is the leading cause of cancer-related death for men and women (1). In the United States alone, more than 213,000 cases of lung cancer will be diagnosed with approximately 160,000 deaths annually $(1,2)$. Non-small cell lung cancer (NSCLC) accounts for 75 to $80 \%$ of lung cancer and patients typically present with advanced disease (3). Currently, treatment options for a patient with locally advanced lung cancer include chemotherapy, radiotherapy and/or surgery (4). Unfortunately, recent studies demonstrate that conventional therapies may have reached a therapeutic plateau as illustrated by the 5-year survival rate for NSCLC, which remains at 15\% (1). Thus, the current therapeutic challenge is to optimize available non-operative strategies by incorporating new agents into current therapeutic regimens. Targeting the tumor vasculature with antiangiogenic agents in combination with radiotherapy is one promising approach (5).

Several studies demonstrate that angiogenesis and the expression of vascular endothelial growth factor (VEGF) and other proangiogenic factors and their receptors correlates with less favorable clinical outcome for lung cancer patients $(6,7)$ yet clinical trials of agents that target these pathways alone have been disappointing. Preclinical studies suggest that monotherapy with antiangiogenic agents will not be sufficient for the treatment of advanced cancer $(8,9)$ given that tumors typically progress before they respond to therapy and that microscopic residual disease persists even after prolonged therapy with these agents. Clinically, bevacizumab, a humanized antibody against VEGF, has shown considerable promise and improved survival for patients with colorectal, breast, or lung cancer when used in combination with chemotherapy (10-13). We hypothesized that targeting both the tumor and its vasculature by VEGF and EGF receptor (VEFGR, EGFR) blockade would improve lung cancer treatment particularly when combined with radiation therapy. To test this hypothesis, we evaluated the feasibility of combining ZD6474, a potent orally available inhibitor of VEGFR2 and to a lesser degree EGFR tyrosine kinase activity (14-19), with radiation therapy in an orthotopic nude mouse model of human NSCLC that closely mimics the patterns of tumor growth observed in the clinic.

\section{METHODS AND MATERIALS}

\section{Cell proliferation assay}

The NCI-H441 human lung adenocarcinoma cell line (American Type Culture Collection, Manassas, VA) was used for all studies and was maintained in Eagle's modified essential medium supplemented with $10 \%$ fetal bovine serum, sodium pyruvate, nonessential amino acids, L-glutamine, vitamin solution, and penicillin-streptomycin (Flow Laboratories, Rockville, MD) at $37^{\circ} \mathrm{C}$ in $5 \% \mathrm{CO}_{2}-95 \%$ air. Cell proliferation was approximated by the 3(4,5-dimethylthiazol-2yl)-2.5-diphenyl-tetrazolium bromide (MTT) dye reduction method (MTT assay) for H441 cells treated with ZD6474, irradiation, the combination of ZD6474 and irradiation, or vehicle alone for up to 72 hours. $\mathrm{H} 441$ cells were cultured for 24 hours and then challenged with 1, 2.5, 5, or $10 \mu \mathrm{M}$ ZD6474 in $0.1 \%$ dimethyl sulfoxide (DMSO) or $0.1 \%$ DMSO alone in fresh medium. After 24 hours the cells were exposed to irradiation (4 Gy given as a single fraction using a $\mathrm{Cs}^{137}$ source at $3.3 \mathrm{~Gy} / \mathrm{min}$ at room temperature) or sham irradiation and cultured for another 72 hours in the same medium. The cells were then stained with MTT and lysed, and absorbency was determined in a plate reader using a 570-nm filter. 


\section{Clonogenic survival assay}

H441 lung adenocarcinoma cells in culture were exposed to $5 \mu \mathrm{M}$ ZD6474 in $0.1 \%$ DMSO or to $0.1 \%$ DMSO alone for 72 hours and then irradiated. For split-dose experiments, lung adenocarcinoma cells were treated with $5 \mu \mathrm{M}$ ZD6474 in $0.1 \%$ DMSO or $0.1 \%$ DMSO alone and then irradiated with a single dose of $4 \mathrm{~Gy}$, or two doses of $2 \mathrm{~Gy}$ with a 4 or 8 hour interval. The total exposure time to ZD6474 was 24 hours. The colony forming ability of cells for each group was determined by trypsinizing and then replating them at defined densities in 50-mm dishes with growth medium. After 10 days of incubation, the cells were stained with $0.5 \%$ crystal violet in absolute ethanol and colonies with more than 50 cells counted under a dissection microscope. Radiation survival curves were plotted after normalization for the cytotoxicity induced by ZD6474. Clonogenic survival curves were constructed from at least three independent experiments by fitting the average survival levels using least squares regression by the linear quadratic model. Recovery ratios of the split dose to the single dose were calculated for the ZD6474-treated and untreated groups.

\section{Orthotopic Lung Adenocarcinoma Model}

Male 6 to 8 week old athymic Ncr (nu/nu) mice were maintained in a specific pathogen-free mouse colony in accordance with regulations and standards of the U.S. Departments of Agriculture and Health and Human Services. Mice were anesthetized with sodium pentobarbital $(50 \mathrm{mg} / \mathrm{kg})$ and placed in the right lateral decubitus position. The skin overlying the left chest wall in the mid-axillary line was prepped with alcohol and incised $(3 \mathrm{~mm})$ and the underlying chest wall visualized. Logarithmically growing $\mathrm{H} 441$ cells $\left(5 \times 10^{5}\right.$ cells in single-cell suspensions of over $95 \%$ viability as determined by Trypan blue exclusion) in 50 $\mu \mathrm{l}$ saline containing $50 \mu \mathrm{g}$ growth factor-reduced Matrigel (Becton Dickinson, San Jose, CA) were injected into the left thorax at the lateral dorsal axillary line. After tumor injection, the mice were turned to the left lateral decubitus position and observed until fully recovered. No anesthesia or surgery-related deaths occurred.

\section{Therapeutic Experiments with ZD6474, irradiation, and/or paclitaxel}

H441 human lung adenocarcinoma cells were injected into the lungs as described above. Eight days after implantation, mice (8/group) were randomly assigned to receive vehicle, fractionated irradiation, paclitaxel, paclitaxel plus irradiation, ZD6474 in 0.5\% Tween 80 in water, or ZD6474 plus irradiation. Radiation to the left lung and mediastinum was delivered to mice immobilized in a customized jig with a positional anterior field using a Pantax $300 \mathrm{kV}$ X-ray unit at a dose rate of $1.3 \mathrm{~Gy} / \mathrm{min}$ to a total dose of $20 \mathrm{~Gy}$ in $4 \mathrm{~Gy}$ fractions 3 times per week (delivered on days $8,10,12,15$, and 17 after tumor implantation). Paclitaxel (200 $\mu \mathrm{g} / \mathrm{mouse}$ ) was injected intraperitoneally once weekly on days 8,15 , and 22 after tumor implantation 2 hours prior to radiotherapy. ZD6474 (15 mg/kg once daily) was administered orally. When mice received ZD6474 and radiotherapy, ZD6474 was given 4 hours prior radiotherapy. Treatment was terminated when controls became moribund and all mice were then sacrificed and autopsied, and tumor tissues harvested. Tumor burden was assessed by weighing bilateral lungs with tumors and mediastinal tissues (including lymph nodes) after removing the heart.

\section{Histology and Immunohistochemistry}

Tumor and adjacent lung tissues from 4 or more mice from each of the treatment groups were frozen in OCT (optimal cutting temperature) cryoembedding compound or formalin fixed and embedded in paraffin and then sectioned and H\&E- or immuno-stained. Sectioned paraffinembedded tissues were used to detect the expression of EGF, EGFR (Zymed, San Francisco, CA), VEGF, VEGFR2, bFGF, MMP-2, and MMP-9 (Santa Cruz Biotechnology, Santa Cruz, CA) as described $(20,21)$. TUNEL was performed using a commercial kit (22). Frozen tissue sections were used for immunofluorescence double stainings for CD31 (Pharmingen, San 
Diego, CA) and activated EGFR (Biosource International, Camarillo, CA), activated VEGFR2 (Oncogene, Cambridge, MA), TUNEL (Promega, Madison, WI), or BrdU incorporation as described $(20,21)$. The reaction intensity of positive cells was measured in 10 random 0.039$\mathrm{mm}^{2}$ fields at $\times 200$ magnification using Optimas Image Analysis software and expressed as the percentage of tumor cell expression to tumor-free tissue (normal lung) expression. TUNELor BrdU-positive endothelial cells were counted in 10 random 0.039 -mm2 fields at $\times 200$ magnification and the percentage of positive cells were calculated. For quantification of the immunohistochemical reaction intensity, the absorbance of positive cells from each of the tumor tissues was measured in 10 random $0.039-\mathrm{mm} 2$ fields at $\times 200$ magnification using the Optimas Image Analysis software. Samples were not counterstained and the absorbance was attributable solely to the product of the immunohistochemical reaction. Receptor or cytoplasmic immunoreactivity was evaluated by computer-assisted image analysis and expressed as percent of tumor cell to tumor-free adjacent tissue expression. For MVD determination, 10 random $0.159-\mathrm{mm}^{2}$ fields at $\times 100$ magnification were captured after staining with anti-CD31 antibody. Microvessels were quantified using Scion software based on the NIH Image program for Macintosh (Scion, Frederick, MD) as described (20).

\section{Statistical analysis}

Data from two independent animal experiments were substantially similar and were combined. Tumor weight and pleural effusion volume were compared using the Mann-Whitney test. The expression levels of EGF, EGFR, VEGF, VEGFR2, bFGF, MMP-2, and MMP-9, and the percentage of apoptotic or proliferating tumor or endothelial cells were compared with the control group by unpaired Students' $t$ test. A p-value of less than 0.05 was considered statistically significant.

\section{RESULTS}

ZD6474 inhibits H441 lung adenocarcinoma cell proliferation after radiation The MTT assay was used to characterize the effects of radiation and/or ZD6474 upon H441 lung adenocarcinoma cell proliferation. ZD6474 alone inhibited cell proliferation in a dose dependent fashion whereas a single $4 \mathrm{~Gy}$ dose of radiation had no discernable effect. Within 72 hours of irradiation the proliferation of the lung cancer cells treated with radiation, as measured by MTT absorbance, was not different from that of non-irradiated cells due to rapid tumor cell repopulation. When ZD6474 was combined with a single 4 Gy dose of radiation, the dose-dependent inhibitory effect of ZD6474 upon H441 cell proliferation was more pronounced even 72 hours after treatment (Fig. 1a).

\section{ZD6474 radiosensitizes $\mathrm{H} 441$ lung adenocarcinoma cells}

Clonogenic survival assays were used to characterize the ability of ZD6474 to sensitize lung adenocarcinoma cells to the effects of radiation. Irradiation alone resulted in a dose-dependent reduction in cell survival and the effect was significantly enhanced by treatment with $5 \mu \mathrm{M}$ of ZD6474 starting 72 hours before and at the time of irradiation compared to control (Fig. 1b). The cell killing induced by 4 Gy irradiation combined with ZD6474 was comparable to that observed for irradiation alone at a dose of $5.3 \mathrm{~Gy}$ irradiation corresponding to an enhancement factor of 1.32 .

\section{ZD6474 inhibits sublethal radiation damage repair}

To determine the ability of ZD6474 to inhibit the repair of sublethal radiation damage, clonogenic cell survival was assayed after exposing lung adenocarcinoma cells to a single 4 GY radiation dose or to 2 fractions of 2 Gy with a 4 or 8 hour interval between fractions. For each of the radiation groups, cells were treated with ZD6474 $(5 \mu \mathrm{M})$ or vehicle starting 24 hours before the last radiation dose. The surviving fraction of vehicle-treated cells in the 4 hour 
split group increased significantly as compared to the single dose irradiated group with a recovery ratio of 1.34 (Fig. 1c). In contrast, the surviving fraction of ZD6474-treated lung adenocarcinoma cells in the 4 hour split group was comparable to that of the single dose irradiated group with a recovery ratio of 1.04 indicating that the repair of sublethal radiation damage was almost completely inhibited by ZD6474 treatment (Fig. 1c). The survival fractions of ZD6474-treated cells during the 8 hour split increased slightly over those from the 4 hour split but the difference was not statistically significant.

\section{ZD6474 treatment enhances radioresponse for orthotopic lung tumors}

After injection of $\mathrm{H} 441$ cells into the left lungs, lung tumors grew rapidly and pleural effusions were detected within 15 days. Diffuse thoracic growth with extensive bilateral mediastinal, axillary, and neck lymphatic metastasis led to significant morbidity within 4 weeks. To determine feasibility and tolerance of thoracic radiotherapy, we first treated mice with a variety of radiation schemes including a single fraction of $14 \mathrm{~Gy}, 8 \mathrm{~Gy}$ once weekly, $5 \mathrm{~Gy}$ twice weekly, 4 Gy 3 times weekly, or 2 Gy 5 times weekly. Based upon these studies, 4 Gy given 3 times weekly to a total dose of $20 \mathrm{~Gy}$ was selected for combination studies with ZD6474. The dose of ZD6474 $(15 \mathrm{mg} / \mathrm{kg})$ was determined in preliminary experiments to result in measurable tumor growth delay without tumor eradication. Radiation therapy was delivered to the left lung and mediastinum of mice using a customized jig developed for these studies (Fig. 2a).

To compare the effects of ZD6474 and paclitaxel upon tumor radioresponse, mice with established left lung adenocarcinomas were treated with vehicle, ZD6474 $(15 \mathrm{mg} / \mathrm{kg} / \mathrm{day}$ po), paclitaxel (200 $\mu \mathrm{g}$ once weekly ip), fractionated radiotherapy (4 Gy three times weekly to a dose of $20 \mathrm{~Gy}$ ), or the combination of ZD6474 or paclitaxel with radiation. Mice were sacrificed when control mice began to show signs of significant morbidity related to lung tumor burden, which typically occurred within 4 weeks, and the experiment was repeated. Tumor burden in the lung and mediastinum, as assessed by total lung weight, increased substantially during the course of the experiment and was only partially offset by treatment with ZD6474, radiation, or paclitaxel alone (Fig. 2b). ZD6474 increased the radioresponse of H441 lung tumors substantially more than paclitaxel and the progression of H441 lung adenocarcinomas was virtually completely inhibited after combined ZD6474 and irradiation (p<0.01, Fig. 2b).

Irradiation had no significant effect on the volume of pleural effusion (Fig. 2c). ZD6474, paclitaxel, or paclitaxel combined with radiation partially prevented the pleural effusion. The combination of ZD6474 and irradiation resulted in a virtual complete prevention of pleural effusions $(p<0.01)$ and did so more effectively than paclitaxel plus irradiation $(p<0.01)$.

\section{ZD6474 and radiation prevents lung tumor dissemination to the chest wall and thoracic lymph nodes}

As is commonly observed for patients with locally advanced lung cancer, we observed substantial tumor dissemination after mice were injected orthotopically with human lung adenocarcinoma cells. Disease progressed from the injected lung to the contralateral lung and throughout the chest cavity (Fig. 3) with invasion of the pleural surface, bones of the chest wall, and metastasis to the regional lymph nodes. The total weight of disseminated lesions in the thorax were $197 \pm 38.1 \mathrm{mg}$ for the control (Fig. 3a), $160 \pm 49.7 \mathrm{mg}$ for radiation alone (Fig. $3 b), 92.6 \pm 31.0 \mathrm{mg}$ for paclitaxel alone ( $<<0.05$ versus control), $47.5 \pm 16.6 \mathrm{mg}$ for paclitaxel plus irradiation ( $\mathrm{p}<0.01$ versus control), $54.0 \pm 14.5 \mathrm{mg}$ for ZD6474 alone (Fig. 3c, $\mathrm{p}<0.01$ versus control) and $17.2 \pm 8.0 \mathrm{mg}$ for ZD6474 plus radiation (Fig. 3d, $\mathrm{p}<0.001$ versus control). Mice treated with ZD6474 (Fig. 3c) or radiation (Fig. 3b) alone had bilateral thoracic chest wall and bony lesions with large tumors observed primarily in the contralateral thorax for the radiation group and bilaterally for the ZD6474 group. In contrast, treatment with combined radiation and ZD6474 almost completely blocked tumor growth in the thoracic wall (Fig. 3d). 
These data show that combining ZD6474 and irradiation results in enhanced anti-tumor efficacy for primary lung tumors and disseminated disease throughout the thorax and regional lymphatics.

\section{Enhanced anti-tumor, anti-vascular and antiangiogenic effects by combined therapy with ZD6474 and radiation}

Lung tumor tissues from each treatment group were subjected to immunohistologic analyses. H\&E staining revealed tumor necrosis in each treatment group, particularly for tumors treated with paclitaxel or ZD6474 plus irradiation (data not shown). To characterize the antiangiogenic effects of each treatment, we determined the microvessel density (MVD) for lung tumors at the conclusion of the experiment (Fig. 4a). Treatment with irradiation or paclitaxel alone had no significant effect upon MVD as compared to control, but there was a marginal decrease when paclitaxel was combined with irradiation. ZD6474 significantly suppressed angiogenesis as evidenced by a substantial decrease in MVD ( $p<0.01$ versus control) and the antiangiogenic effect was further enhanced when ZD6474 was combined with radiation ( $<<0.001$ versus control).

To differentiate between tumor and tumor-associated endothelial cell proliferation and apoptosis, double immunofluorescence assays of CD31/ bromodeoxyuridine (BrdU) or CD31/ TUNEL were performed. ZD6474 treatment resulted in decreased proliferation (CD31/BrdU) and increased apoptosis (CD31/TUNEL) for both tumor cells and tumor-associated endothelial cells in H441 tumors (Fig. 4a,b) and the effects were further enhanced when ZD6474 was combined with radiation (see Fig. $4 \mathrm{~b}$ for the $\mathrm{p}$ values). The ability of ZD6474 to enhance endothelial cell apoptosis and impair endothelial cell proliferation suggest that ZD6474 induces both anti-vascular and antiangiogenic effects.

\section{Blockade of activation of VEGFR2 and EGFR for tumor and tumor-associated endothelial cells}

ZD6474 primarily targets VEGFR2 but also has activity against EGFR. To assess the effects of ZD6474 alone and in combination with radiotherapy we analyzed endothelial and tumor cell expression of each receptor and their respective ligands. Representative images for EGF, EGFR, pEGFR/CD31, VEGF, VEGFR2, and pVEGFR2/CD31 are shown in Figure 5a. EGFR was expressed and activated by both tumor cells and endothelial cells (Fig. 5a) consistent with previous studies (20) showing a correlation between tumor cell expression of EGF and/or TGF $\alpha$ and the expression of EGFR by the tumor endothelial cells. Both tumor cells and endothelial cells also expressed and activated VEGFR2 (Fig. 5a). Radiation therapy resulted in an increased expression of both VEGFR2 and EGFR in lung tumors relative to control whereas paclitaxel alone only increased the expression of EGFR (Fig. 5b). ZD6474 treatment had little effect upon expression of EGFR and marginally decreased the expression of VEGFR2 but did inhibit the phosphorylation of both of these receptors (Fig. 5a). The addition of paclitaxel or ZD6474 to radiation offset the increased expression of VEGFR2 but not that of EGFR (Fig. 5b).

Double staining for CD31/pVEGFR2 and CD31/pEGFR (Fig. 5a) revealed that the activation of VEGFR2 and EGFR in both tumor cells and tumor-associated endothelial cells in tumor tissues was blocked by ZD6474 alone and in combination with radiotherapy. Paclitaxel alone and in combination with radiation significantly increased EGFR expression in tumor cells but neither paclitaxel nor irradiation affected EGFR phosphorylation. Radiotherapy did not significantly affect VEGF or EGF expression in lung tumors at the time point tested but did induce increased basic fibroblast growth factor (bFGF) expression (Fig. 5b,c). 
Lung tumor VEGF and EGF expression decreased after paclitaxel or ZD6474 alone or in combination with radiotherapy (Fig. 5b). The most profound decrease in lung tumor VEGF expression was observed in the combined ZD6474 and radiation group. Treatment with radiation, as compared to control, had little effect upon lung tumor expression of matrix metalloproteinase-2 and -9 (MMP-2 and MMP-9). However, MMP-2 and MMP-9 expression increased after paclitaxel treatment and decreased after ZD6474 treatment (data not shown).

\section{DISCUSSION}

Recent clinical studies for lung cancer patients demonstrate that conventional therapies may have reached a therapeutic plateau as illustrated by the 5-year survival rate of $14 \%$ for locally advanced NSCLC (1). Concurrent or sequential chemoradiotherapy is the current standard of care for patients with locally advanced lung cancer but has only modestly improved survival for lung cancer patients $(23,24)$ and the majority of patients with locally advanced stage III NSCLC have tumors that remain unresectable after aggressive neoadjuvant therapy. In the metastatic setting, treatments for lung cancer are essentially palliative and the prognosis of patients with advanced lung cancer remains poor (25). Thus, the current therapeutic challenge is to optimize available non-operative strategies by incorporating new agents into current therapeutic regimens. In our study using an orthotopic lung cancer model that closely recapitulates human disease, we found that targeting the activation of VEGFR2, and to a lesser degree EGFR, with ZD6474 substantially improved radioresponse and was therapeutically superior to combined radiotherapy and paclitaxel.

The efficacy of radiotherapy is influenced by multiple factors, including intrinsic tumor radiosensitivity, cellular capacity for repair and repopulation, and oxygenation status. In our in vitro clonogenic cell survival studies for H441 lung adenocarcinoma cells, ZD6474 treatment impaired the efficiency of the repair of sublethal radiation damage even after a shortterm exposure (4 hours) of the lung cancer cells to ZD6474. The survival fraction for the lung cancer cells after irradiation increased with prolonged exposure to ZD6474, suggesting that DNA repair might initially be inhibited by ZD6474 but that other repair pathways might be activated during extended treatment. However, identifying the mechanisms by which ZD6474 inhibits radiation repair requires further investigation.

A number of studies have examined the effects of radiation therapy combined with antiangiogenic agents and have demonstrated that that these agents enhance radioresponse (5). The majority of these studies relied upon subcutaneous or intramuscular tumor xenograft models. However, xenografts may not fully address the interaction between the specific organ environment and tumor cells (26) and gene expression for tumors is markedly altered when they are implanted subcutaneously as compared to orthotopically (27). Moreover, microenvironmental factors, especially those controlling angiogenesis, are critical regulators of tumor growth and spread. Indeed, we recently reported that treatment with paclitaxel was effective against human lung cancer cells growing subcutaneously but was virtually ineffective when the cells were growing in the lung $(28,29)$. Our mouse model of human lung cancer allows for the study of critical interactions between tumor and stroma in the lung microenvironment and our data strongly suggest that it will be prudent to include ZD6474 and other angiogenesis inhibitors in the combined modality treatment of lung cancer.

One potential means of tumor resistance to antiangiogenic therapy is the increased expression of proangiogenic factors $(30,31)$. Increased VEGF production by tumor cells shortly after irradiation (32) may also contribute to resistance to radiotherapy that induces rapid apoptosis of endothelial cells in highly proliferative tissues $(33,34)$. In our model, VEGF and EGF were not significantly impacted by radiation therapy when tumors were analyzed several days after delivery of radiation therapy suggesting that radiation therapy did not induce a sustained over- 
expression of these growth factors. However, VEGFR2, EGFR, and bFGF expression increased substantially after radiation therapy to lung tumors. The addition of ZD6474 to radiation therapy offset the activation of VEGFR2 and EGFR and blocked the radiation-associated overexpression of bFGF and VEGFR2 yet had no effect upon the over-expression of EGFR for lung tumors.

Although the effects of VEGFR signaling were initially thought to be specific for the vasculature, VEGF plays a role in multiple processes (35-38) and recent data suggests that colon cancer cell expression of VEGFR1 contributes to colon cancer cell motility and invasiveness with little direct effect upon proliferation (39). Our data shows that H441 human lung adenocarcinoma cells express VEGFR2 and that this expression is substantially increased after radiotherapy. These data suggest that VEGF and its receptors may play a direct role in tumor cell survival after cytotoxic stress and may contribute to resistance to therapy. Strategies that target VEGF and its receptors therefore have the potential for direct and indirect effects upon a tumor and its vasculature and may overcome survival pathways activated by irradiation. However, it will be critical to screen for the expression of both the ligand(s) and receptor(s) by tumor and tumor-associated endothelial cells when designing therapeutic strategies for antiangiogenic and other biologically targeted agents.

VEGF is critical for endothelial cell survival, integrity, and function $(40,41)$ and endogenous regulators of VEGF have been implicated in pathologic hypertension observed in preeclampsia (42). As a result, some anti-VEGF agents could be associated with toxicity due to effects upon and/or disruption of normal vasculature. Clinical trials of agents that target VEGF have identified hemorrhage and thrombosis as complications for some VEGF inhibitors $(43,44)$ and in lung cancer VEGF antagonism has been associated with fatal hemorrhage that may be due in part to disruption of the normal vascular integrity. The combination of radiotherapy with inhibitors of VEGF/VEGFR signaling may decrease the risks of hemorrhage given that radiotherapy alone is frequently used to prevent bleeding and studies of the combination of these two modalities are timely and relevant.

Willett and colleagues (45) designed a Phase I study in which patients with locally advanced rectal adenocarcinoma were treated with bevacizumab for 2 weeks, followed by bevacizumab with 5-fluorouracil and radiation therapy, and surgery 7 weeks after treatment completion. In patients with poor prognosis lung cancer, celecoxib was administered concurrently with thoracic radiotherapy. The treatment resulted in actuarial local progression-free survival of $66.0 \%$ at 1 year and $42.2 \%$ at 2 years (46). In our preclinical studies, the strategy of targeting VEGFR2 and to a lesser degree EGFR signaling with ZD6474 significantly enhanced the antiangiogenic, anti-vascular, and anti-tumor effects of radiotherapy for human lung cancer growing orthotopically in mice and was superior to the combination of radiation therapy and chemotherapy. Studies are now underway to identify the optimal sequencing of ZD6474 and other antiangiogenic agents with chemotherapy and radiotherapy. Clinical trials of these strategies are warranted although therapy will have to be monitored closely and optimized for each patient.

\section{Acknowledgements}

Grant Support: Supported in part by NIH Grant CA-06294, MD Anderson Physician Scientist Awards (M.S.O. and R.S.H.), Department of Defense grant DAMD 17-02-1-0706, and an AstraZeneca research grant.

\section{References}

1. Weir HK, Thun MJ, Hankey BF, et al. Annual report to the nation on the status of cancer, 1975-2000, featuring the uses of surveillance data for cancer prevention and control. JNCI Cancer Spectrum 2003;95:1276-1299. 
2. Jemal A, Siegel R, Ward E, et al. Cancer statistics, 2007. CA Cancer J Clin 2007;57:43-66. [PubMed: 17237035]

3. Mountain CF, Lukeman JM, Hammar SP, et al. Lung cancer classification: the relationship of disease extent and cell type to survival in a clinical trials population. J Surg Oncol 1987;35:147-156. [PubMed: 3037195]

4. Fossella, FV.; Komaki, R.; Putnam, JB. Lung Cancer. New York: Springer-Verlag; 2003.

5. O'Reilly MS. Radiation combined with antiangiogenic and antivascular agents. Semin Radiat Oncol 2006;16:45-50. [PubMed: 16378906]

6. Bremnes RM, Camps C, Sirera R. Angiogenesis in non-small cell lung cancer: the prognostic impact of neoangiogenesis and the cytokines VEGF and bFGF in tumours and blood. Lung Cancer 2006;51:143-158. [PubMed: 16360975]

7. Mineo TC, Ambrogi V, Baldi A, et al. Prognostic impact of VEGF, CD31, CD34, and CD105 expression and tumour vessel invasion after radical surgery for IB-IIA non-small cell lung cancer. J Clin Pathol 2004;57:591-597. [PubMed: 15166262]

8. Boehm T, Folkman J, Browder T, O'Reilly MS. Antiangiogenic therapy of experimental cancer does not induce acquired drug resistance. Nature 1997;390:404-407. [PubMed: 9389480]

9. O'Reilly MS, Holmgren L, Shing Y, et al. Angiostatin: a novel angiogenesis inhibitor that mediates the suppression of metastases by a Lewis lung carcinoma. Cell 1994;79:315-328. [PubMed: 7525077]

10. Herbst RS, Johnson DH, Mininberg E, et al. Phase I/II trial evaluating the anti-vascular endothelial growth factor monoclonal antibody bevacizumab in combination with the HER-1/epidermal growth factor receptor tyrosine kinase inhibitor erlotinib for patients with recurrent non-small-cell lung cancer. J Clin Oncol 2005;23:2544-2555. [PubMed: 15753462]

11. Hurwitz H, Fehrenbacher L, Novotny W, et al. Bevacizumab plus irinotecan, fluorouracil, and leucovorin for metastatic colorectal cancer. N Engl J Med 2004;350:2335-2342. [PubMed: 15175435]

12. Miller KD, Chap LI, Holmes FA, et al. Randomized phase III trial of capecitabine compared with bevacizumab plus capecitabine in patients with previously treated metastatic breast cancer. J Clin Oncol 2005;23:792-799. [PubMed: 15681523]

13. Sandler AB, Johnson DH, Herbst RS. Anti-vascular endothelial growth factor monoclonals in nonsmall cell lung cancer. Clin Cancer Res 2004;10:4258s-4262s. [PubMed: 15217970]

14. Carlomagno F, Vitagliano D, Guida T, et al. ZD6474, an orally available inhibitor of KDR tyrosine kinase activity, efficiently blocks oncogenic RET kinases. Cancer Res 2002;62:7284-7290. [PubMed: 12499271]

15. Ciardiello F, Bianco R, Caputo R, et al. Antitumor activity of ZD6474, a vascular endothelial growth factor receptor tyrosine kinase inhibitor, in human cancer cells with acquired resistance to antiepidermal growth factor receptor therapy. Clin Cancer Res 2004;10:784-793. [PubMed: 14760102]

16. Frederick B, Gustafson D, Bianco C, Ciardiello F, Dimery I, Raben D. ZD6474, an inhibitor of VEGFR and EGFR tyrosine kinase activity in combination with radiotherapy. Int $\mathrm{J}$ Radiat Oncol Biol Phys 2006;64:33-37. [PubMed: 16377413]

17. Hennequin LF, Stokes ES, Thomas AP, et al. Novel 4-anilinoquinazolines with C-7 basic side chains: design and structure activity relationship of a series of potent, orally active, VEGF receptor tyrosine kinase inhibitors. J Medicinal Chem 2002;45:1300-1312.

18. Wedge SR, Ogilvie DJ, Dukes M, et al. ZD6474 inhibits vascular endothelial growth factor signaling, angiogenesis, and tumor growth following oral administration. Cancer Res 2002;62:4645-4655. [PubMed: 12183421]

19. Williams KJ, Telfer BA, Brave S, et al. ZD6474, a potent inhibitor of vascular endothelial growth factor signaling, combined with radiotherapy: schedule-dependent enhancement of antitumor activity. Clin Cancer Res 2004;10:8587-8593. [PubMed: 15623642]

20. Baker CH, Kedar D, McCarty MF, et al. Blockade of epidermal growth factor receptor signaling on tumor cells and tumor-associated endothelial cells for therapy of human carcinomas. Am J Pathol 2002;161:929-938. [PubMed: 12213721] 
21. Huang S, Van Arsdall M, Tedjarati S, et al. Contributions of stromal metalloproteinase-9 to angiogenesis and growth of human ovarian carcinoma in mice. J Natl Cancer Inst 2002;94:11341142. [PubMed: 12165638]

22. Yigitbasi OG, Younes MN, Doan D, et al. Tumor cell and endothelial cell therapy of oral cancer by dual tyrosine kinase receptor blockade. Cancer Res 2004;64:7977-7984. [PubMed: 15520205]

23. Curran W, Scott C, Langer C, et al. Phase III comparison of sequential vs concurrent chemoradiation for patients (Pts) with unresected Stage III non-small cell lung cancer (NSCLC): Initial report of Radiation Therapy Oncology Group (RTOG) 9410 [Abstract]. Proc ASCO 2000;18:484a.

24. Furuse K, Fukuoka M, Kawahara M, et al. Phase III study of concurrent versus sequential thoracic radiotherapy in combination with mitomycin, vindesine, and cisplatin in unresectable stage III nonsmall-cell lung cancer. J Clin Oncol 1999;17:2692-2699. [PubMed: 10561343]

25. Schiller JH, Harrington D, Belani CP, et al. Comparison of four chemotherapy regimens for advanced non-small-cell lung cancer. N Engl J Med 2002;346:92-98. [PubMed: 11784875]

26. Morikawa K, Walker SM, Nakajima M, Pathak S, Jessup JM, Fidler IJ. Influence of organ environment on the growth, selection, and metastasis of human colon carcinoma cells in nude mice. Cancer Res 1988;48:6863-6871. [PubMed: 2846163]

27. Camphausen K, Purow B, Sproull M, et al. Influence of in vivo growth on human glioma cell line gene expression: Convergent profiles under orthotopic conditions. Proc Natl Acad Sci U S A 2005;102:8287-8292. [PubMed: 15928080]

28. Onn A, Isobe T, Itasaka S, et al. Development of an orthotopic model to study the biology and therapy of primary human lung cancer in nude mice. Clin Cancer Res 2003;9:5532-5539. [PubMed: 14654533]

29. Onn A, Isobe T, Wu W, et al. Epidermal growth factor receptor tyrosine kinase inhibitor does not improve paclitaxel effect in an orthotopic mouse model of lung cancer. Clin Cancer Res 2004;10:8613-8619. [PubMed: 15623645]

30. Viloria-Petit A, Crombet T, Jothy S, et al. Acquired resistance to the antitumor effect of epidermal growth factor receptor-blocking antibodies in vivo: a role for altered tumor angiogenesis. Cancer Res 2001;61:5090-5101. [PubMed: 11431346]

31. Yu JL, Rak JW, Coomber BL, Hicklin DJ, Kerbel RS. Effect of p53 status on tumor response to antiangiogenic therapy. Science 2002;295:1526-1528. [PubMed: 11859195]

32. Gorski DH, Beckett MA, Jaskowiak NT, et al. Blockage of the vascular endothelial growth factor stress response increases the antitumor effects of ionizing radiation. Cancer Res 1999;59:3374-3378. [PubMed: 10416597]

33. Garcia-Barros M, Paris F, Cordon-Cardo C, et al. Tumor response to radiotherapy regulated by endothelial cell apoptosis. Science 2003;300:1155-1159. [PubMed: 12750523]

34. Paris F, Fuks Z, Kang A, et al. Endothelial apoptosis as the primary lesion initiating intestinal radiation damage in mice. Science 2001;293:293-297. [PubMed: 11452123]

35. Carmeliet P, Storkebaum E. Vascular and neuronal effects of VEGF in the nervous system: implications for neurological disorders. Semin Cell Dev Biol 2002;13:39-53. [PubMed: 11969370]

36. Gerber HP, Malik AK, Solar GP, et al. VEGF regulates haematopoietic stem cell survival by an internal autocrine loop mechanism. Nature 2002;417:954-958. [PubMed: 12087404]

37. LeCouter J, Moritz DR, Li B, et al. Angiogenesis-independent endothelial protection of liver: role of VEGFR-1. Science 2003;299:890-893. [PubMed: 12574630]

38. Ohm JE, Gabrilovich DI, Sempowski GD, et al. VEGF inhibits T-cell development and may contribute to tumor-induced immune suppression. Blood 2003;101:4878-4886. [PubMed: 12586633]

39. Fan F, Wey JS, McCarty MF, et al. Expression and function of vascular endothelial growth factor receptor-1 on human colorectal cancer cells. Oncogene 2005;24:2647-2653. [PubMed: 15735759]

40. Alon T, Hemo I, Itin A, Pelee J, Stone J, Keshet E. VEGF acts as a survival factor for newly formed retinal vessels and has implications for retinopathy of prematurity. Nature Med 1995;1:1024-1028. [PubMed: 7489357]

41. Nor JE, Christensen J, Mooney DJ, Polverini PJ. VEGF-mediated angiogenesis is associated with enhanced endothelial cell survival and induction of Bcl-2 expression. Am J Pathol 1999;154:375384. [PubMed: 10027396] 
42. Levine RJ, Maynard SE, Qian C, et al. Circulating angiogenic factors and the risk of preeclampsia. N Engl J Med 2004;350:672-683. [PubMed: 14764923]

43. Johnson DH, Fehrenbacher L, Novotny WF, et al. Randomized phase II trial comparing bevacizumab plus carboplatin and paclitaxel with carboplatin and paclitaxel alone in previously untreated locally advanced or metastatic non-small-cell lung cancer. J Clin Oncol 2004;22:2184-2191. [PubMed: 15169807]

44. Kuenen BC, Rosen L, Smit EF, et al. Dose-finding and pharmacokinetic study of cisplatin, gemcitabine, and SU5416 in patients with solid tumors. J Clin Oncol 2002;20:1657-1667. [PubMed: 11896117]

45. Willett CG, Boucher Y, di Tomaso E, et al. Direct evidence that the VEGF-specific antibody bevacizumab has antivascular effects in human rectal cancer. Nature Med 2004;10:145-147. [PubMed: 14745444]

46. Liao Z, Komaki R, Milas L, et al. A phase I clinical trial of thoracic radiotherapy and concurrent celecoxib for patients with unfavorable performance status inoperable/unresectable non-small cell lung cancer. Clin Cancer Res 2005;11:3342-3348. [PubMed: 15867233] 


\section{Figure 1A}

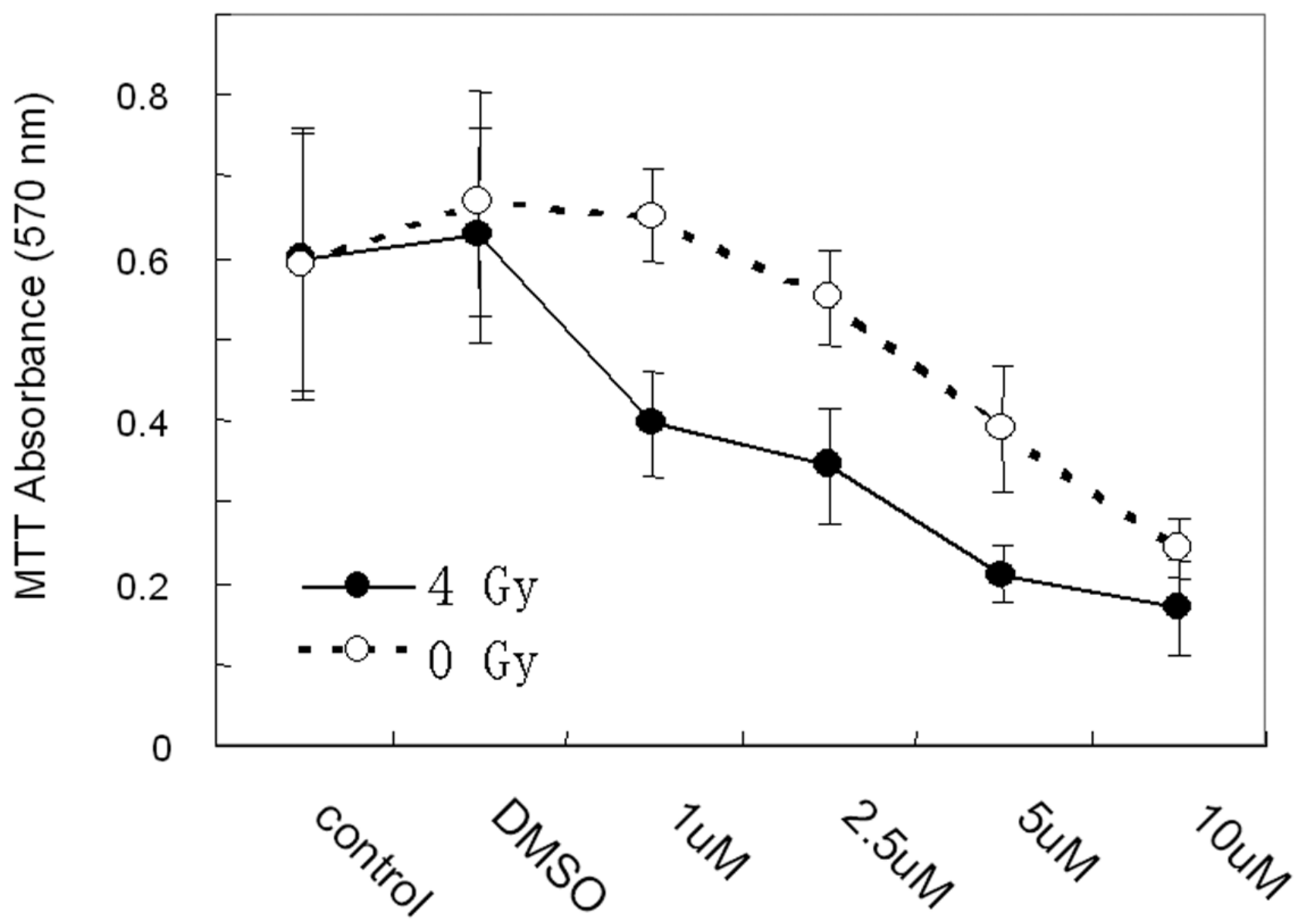


Figure 1B

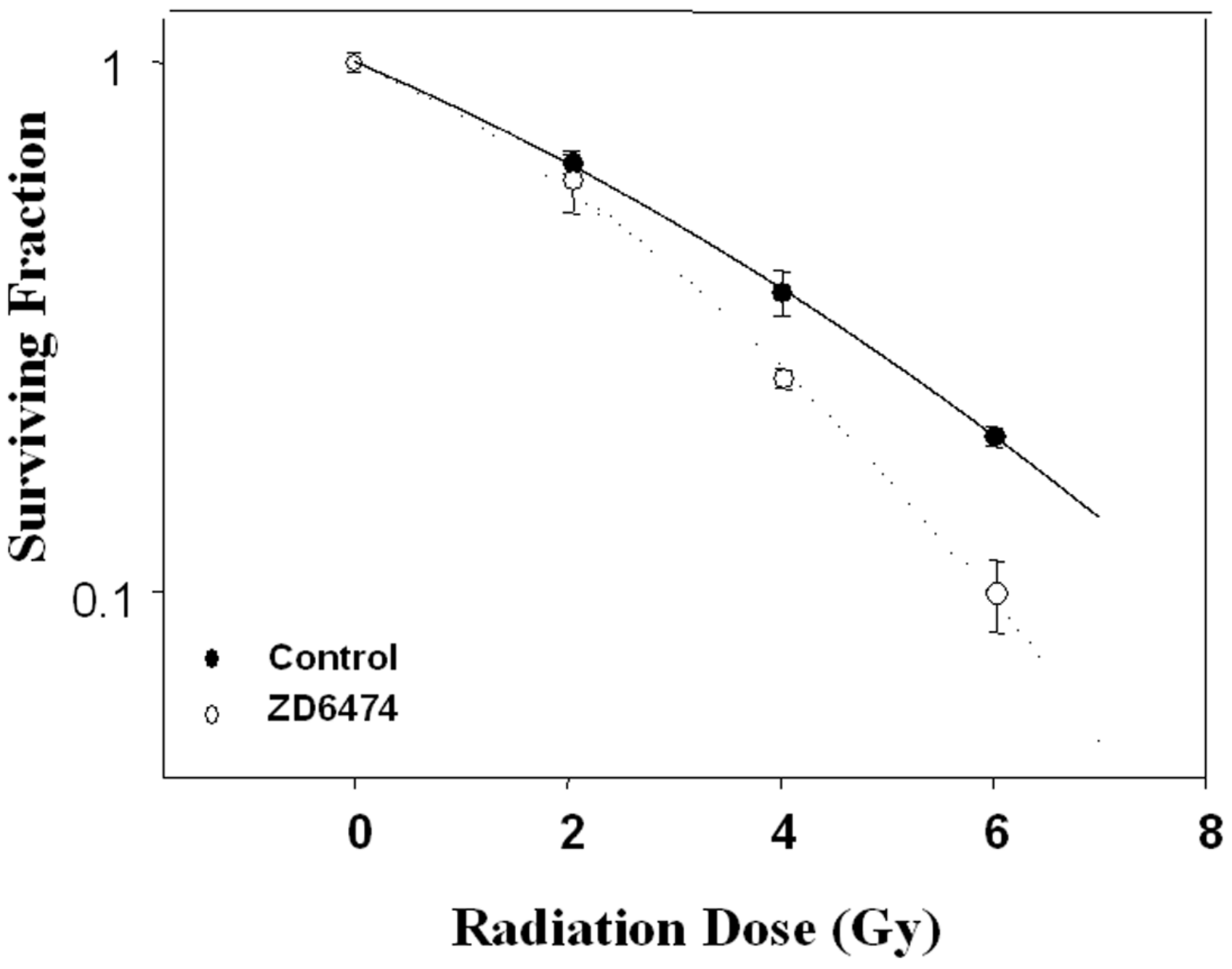

Int J Radiat Oncol Biol Phys. Author manuscript; available in PMC 2007 December 24. 


\section{Figure 1C (revised)}

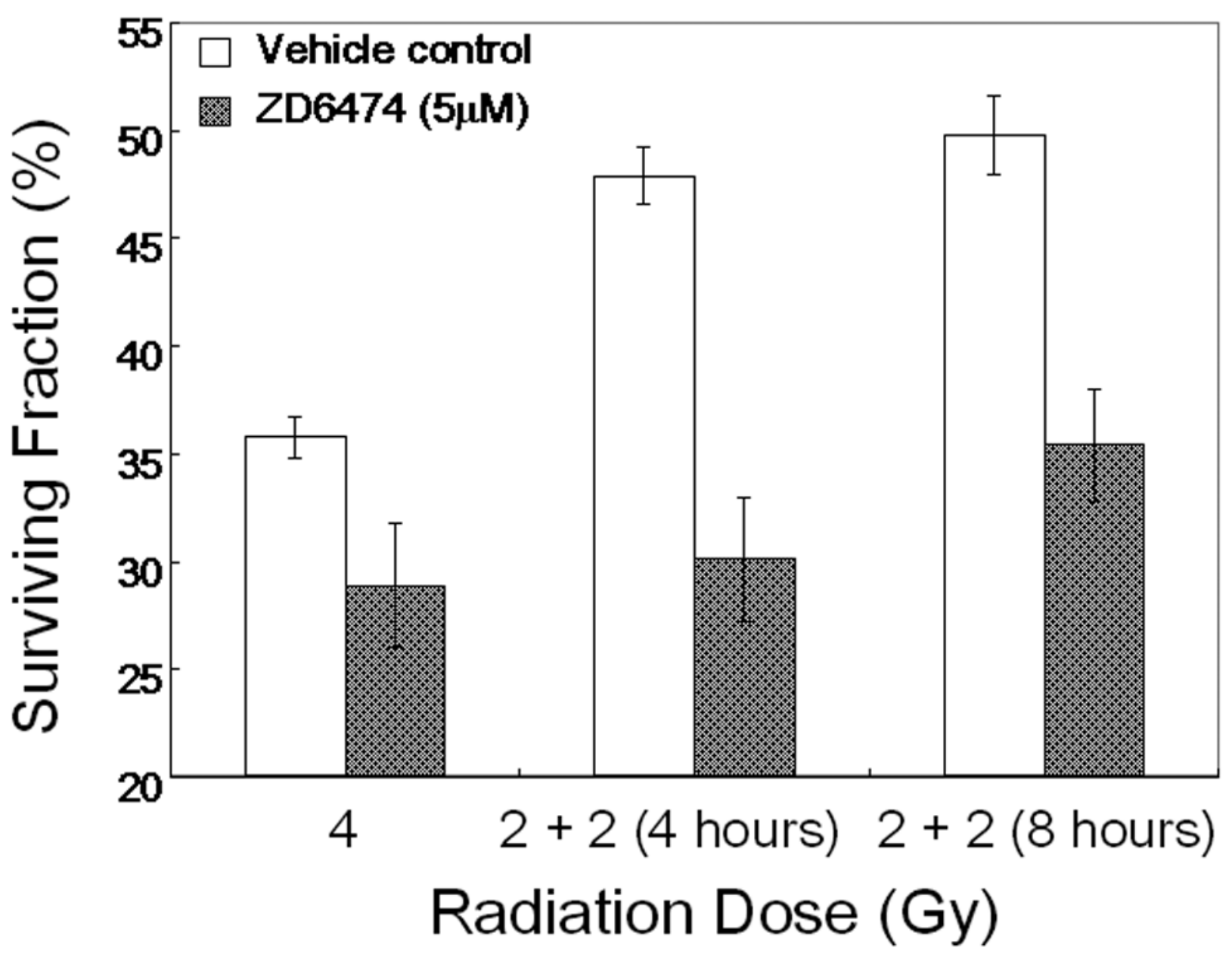

Figure 1.

In vitro studies of ZD6474 and irradiation for H441 lung adenocarcinoma cells. Each data point represents the mean \pm standard error from 3 independent experiments. A, Effect of ZD6474 on proliferation after irradiation or sham treatment, as determined by MTT assay. Lung cancer cells were pretreated with the indicated concentrations of ZD6474 or vehicle and then irradiated. Proliferation was determined 72 hours later. $B$, Clonogenic survival for H441 cells. Clonogenic survival curves were generated after treatment with ZD6474 (5 $\mu \mathrm{M})$ or vehicle starting 72 hours before irradiation. $C$, Clonogenic survival assay after single and split doses of radiation with and without ZD6474 treatment. H441 cells were treated with ZD6474 or vehicle and then exposed to either a single radiation dose (4 Gy) or two doses of $2 \mathrm{~Gy}(2+2)$ 4 or 8 hours apart. 


\section{Figure 2A}

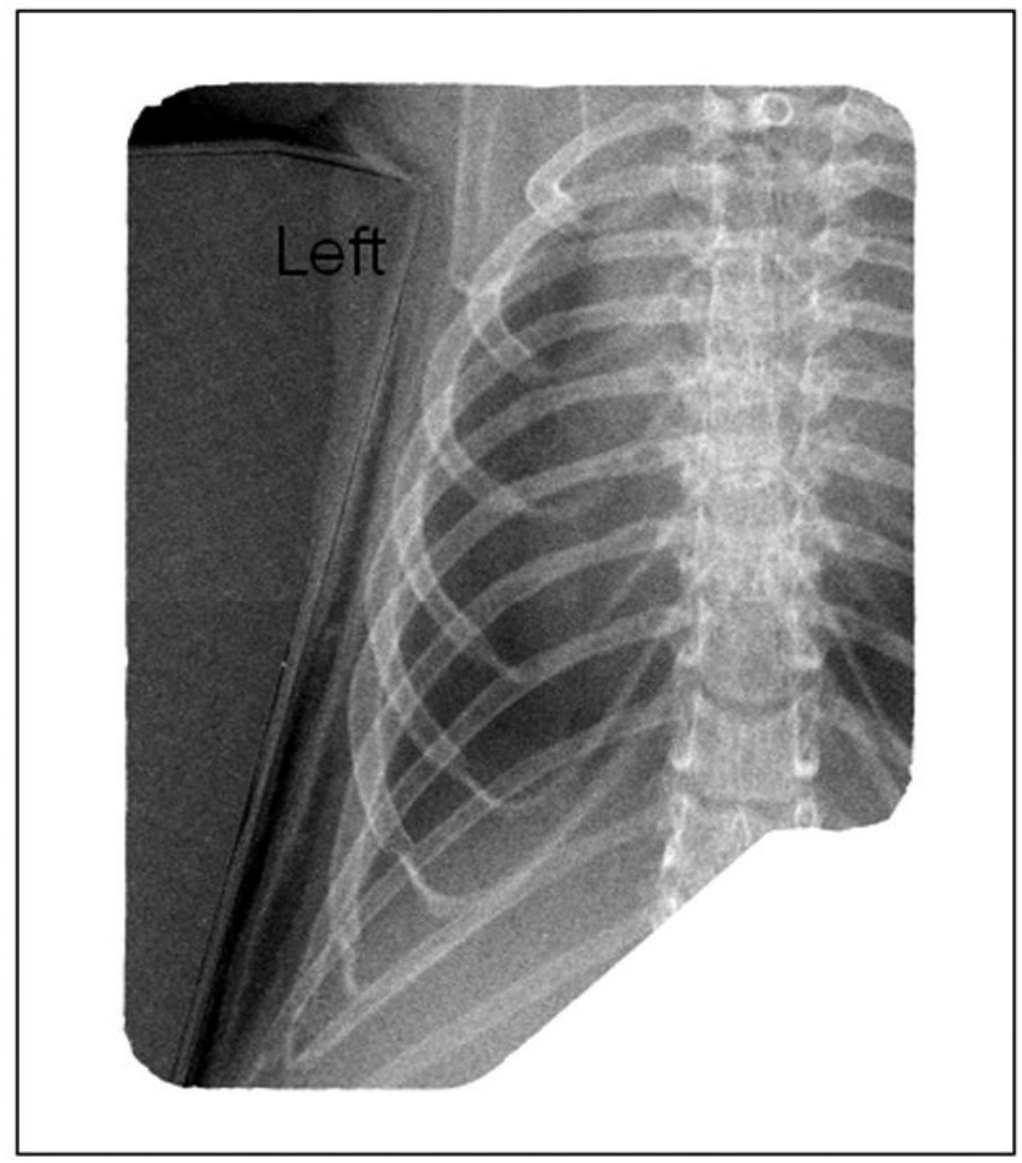


Figure 2B

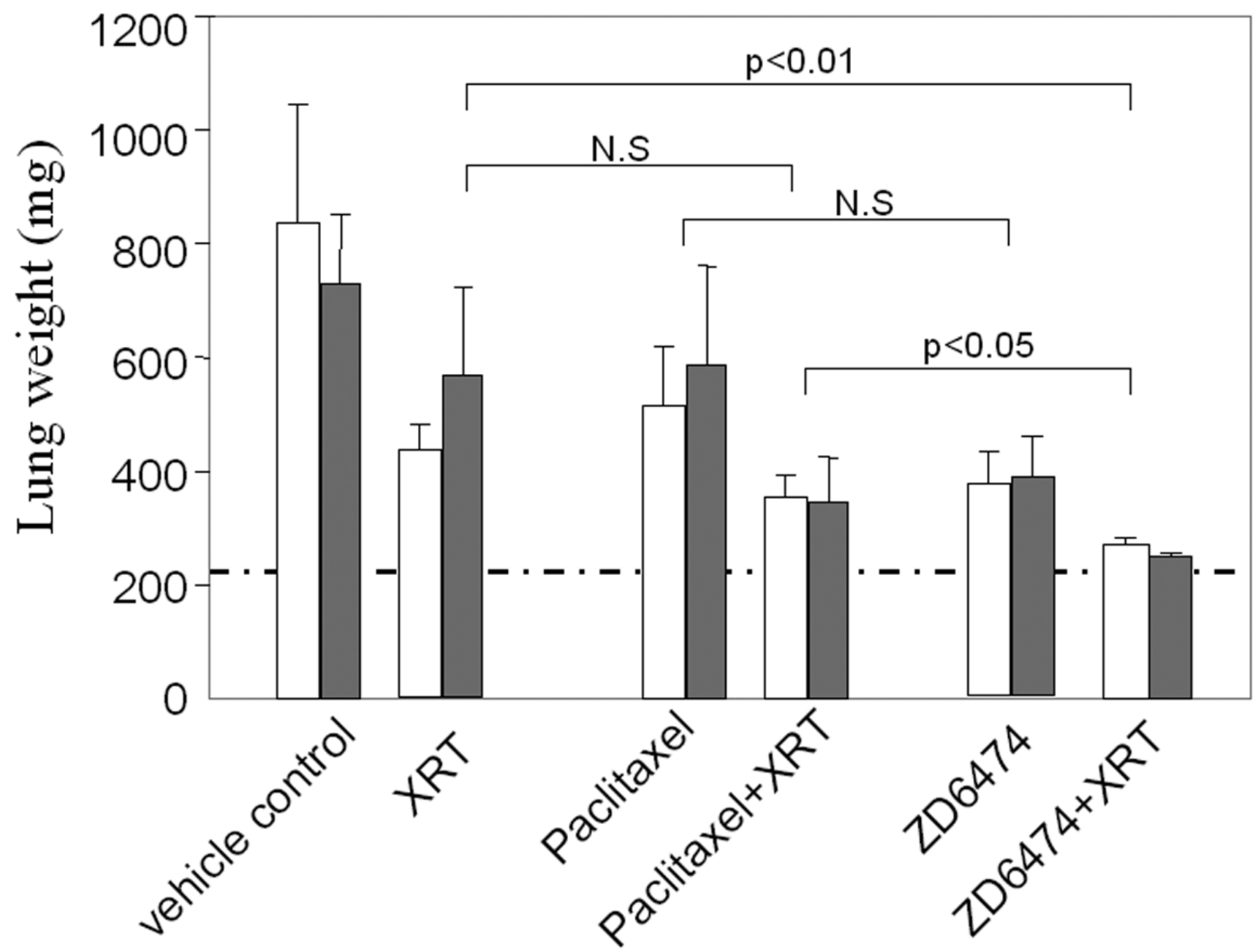




\section{Figure 2C}

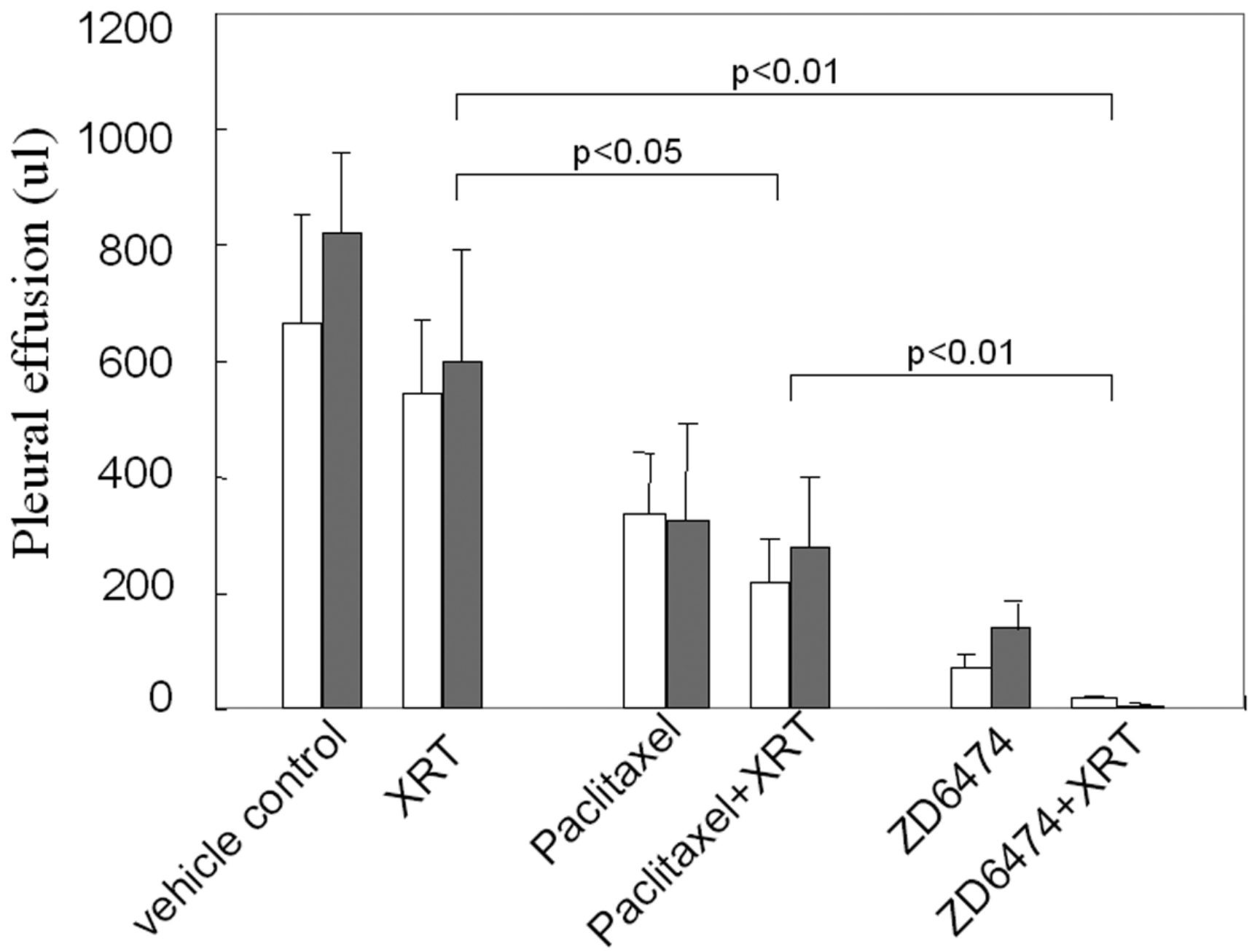

Figure 2.

Anti-tumor and radiosensitizing effects of ZD6474 for human lung cancer in an orthotopic model. $A$, Delivery of radiotherapy to the thorax. $B$, Lung tumor burden as assessed by the combined weight of both lungs, primary tumor, mediastinal tissues excluding the heart, and mediastinal metastases. Normal lung weight for age-matched mice is indicated by the dotted horizontal line. Data are plotted as means \pm standard error for two independent experiments (white or gray bars) with p values as indicated. $C$, Pleural effusion volume. Data are plotted as means \pm standard error for two independent experiments (white or gray bars) with $\mathrm{p}$ values as indicated. 


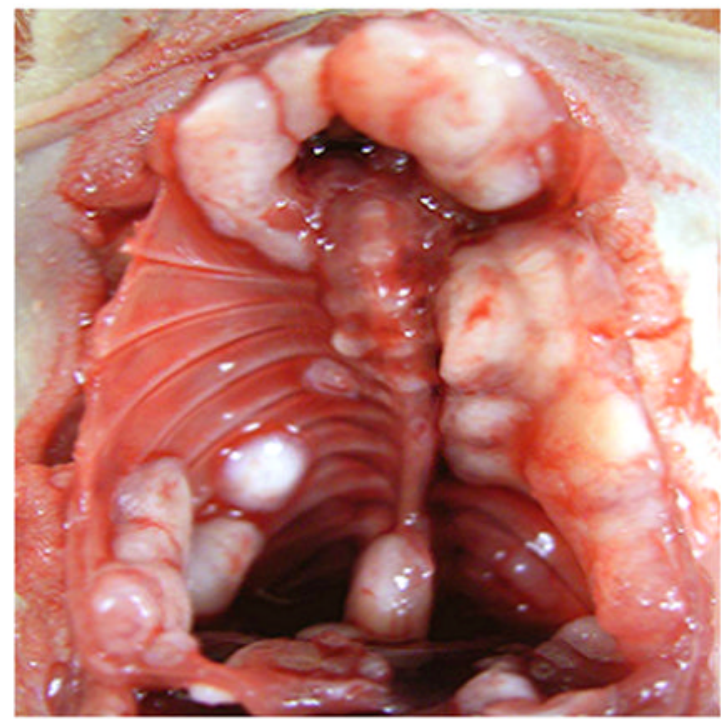

A. Control

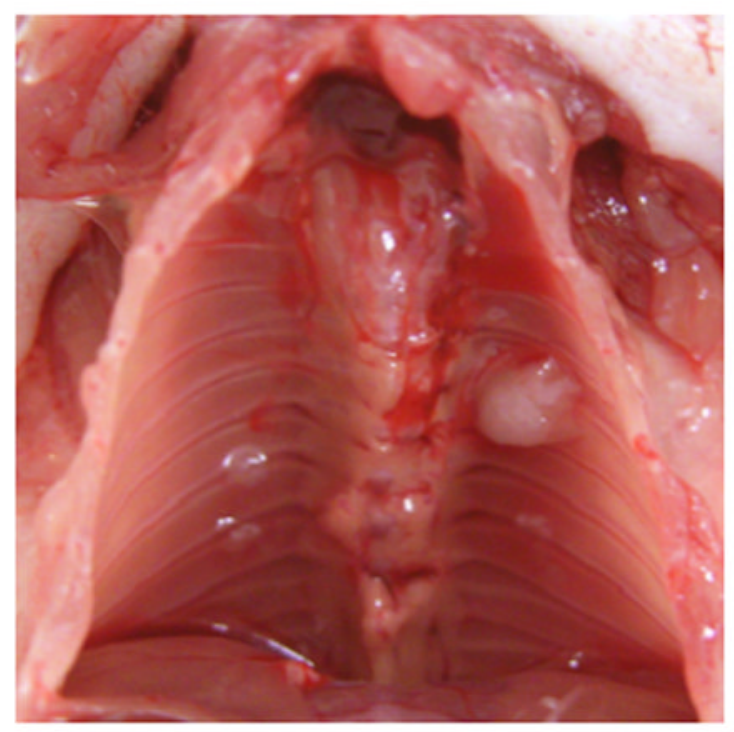

C. ZD6474

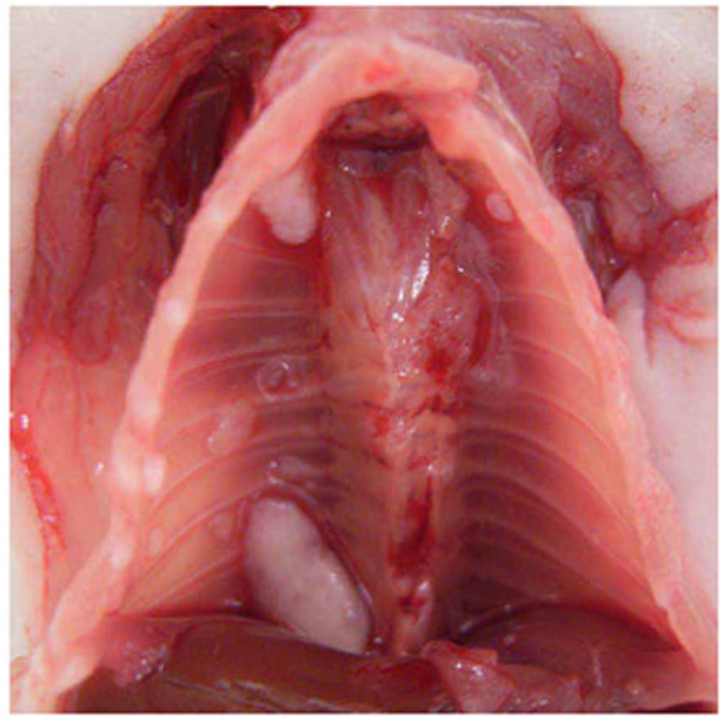

B. XRT

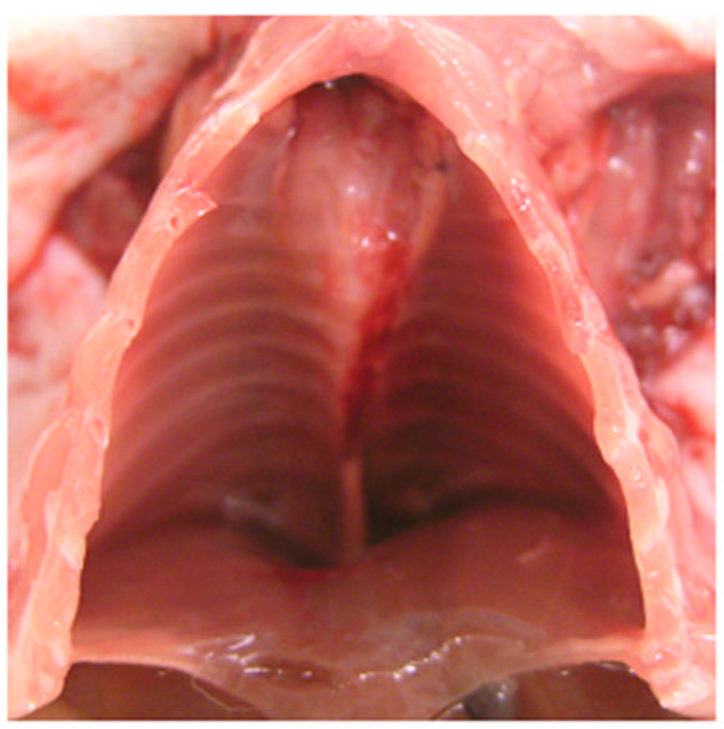

D. ZD6474 + XRT

Figure 3.

Representative images of thoracic chest wall and lymph node metastases. The lungs and mediastinal structures have been removed. 
Figure 4A
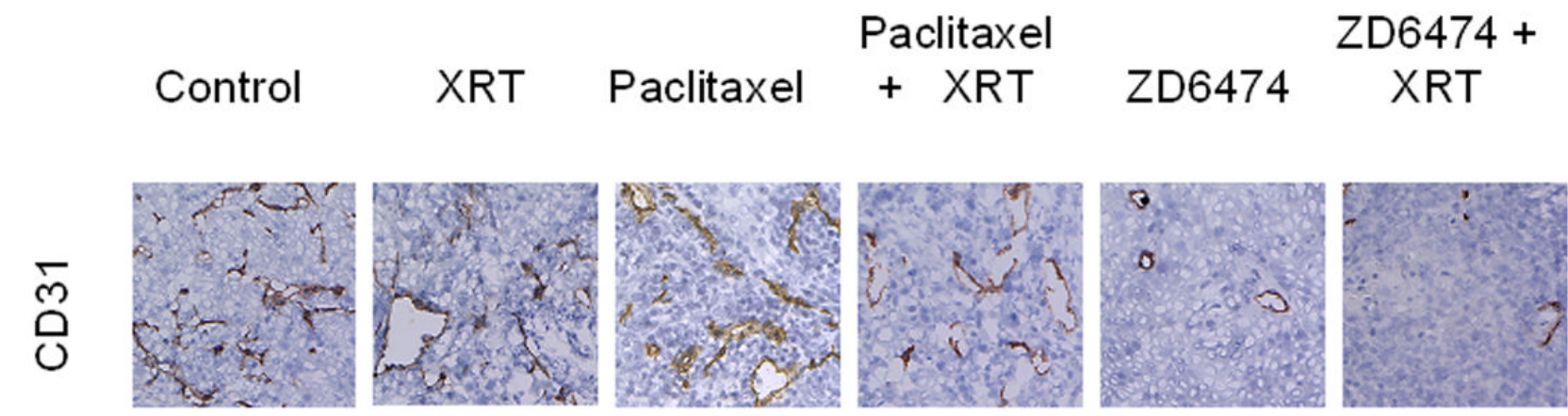

$$
\text { ํㅡㄹ }
$$
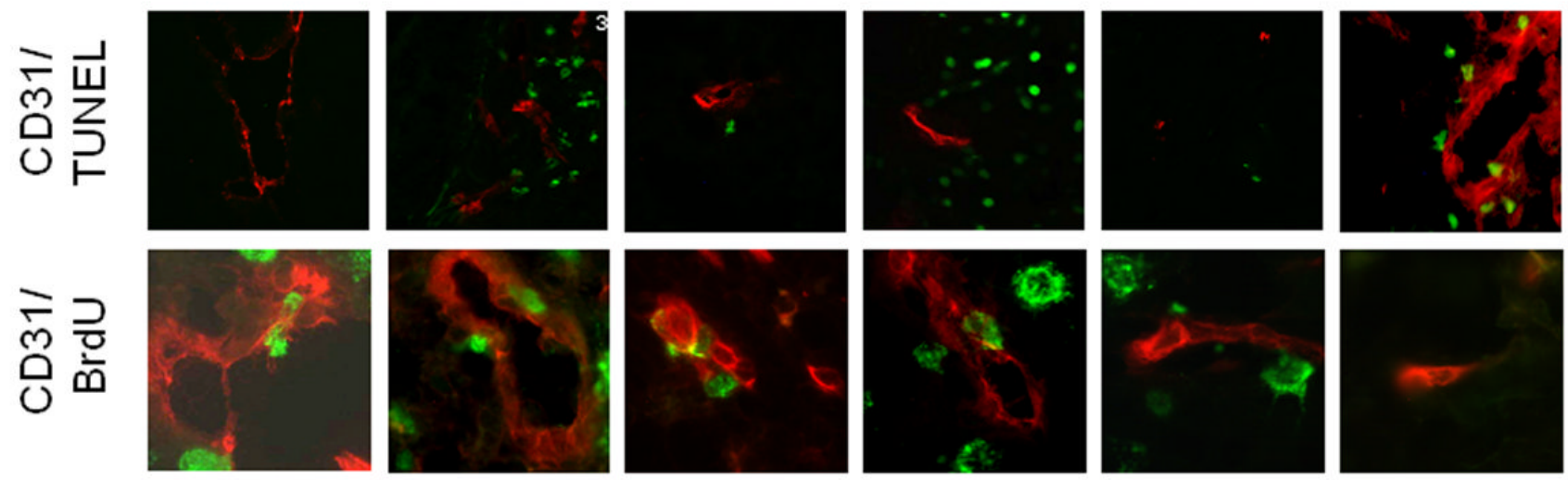

MVD $\quad 55 \pm 3.3 \quad 52 \pm 7.3 \quad 55 \pm 3.3 \quad 42 \pm 4.6 \quad 31 \pm 3.5 \quad 16 \pm 1.9$ 


\section{Figure 4B}
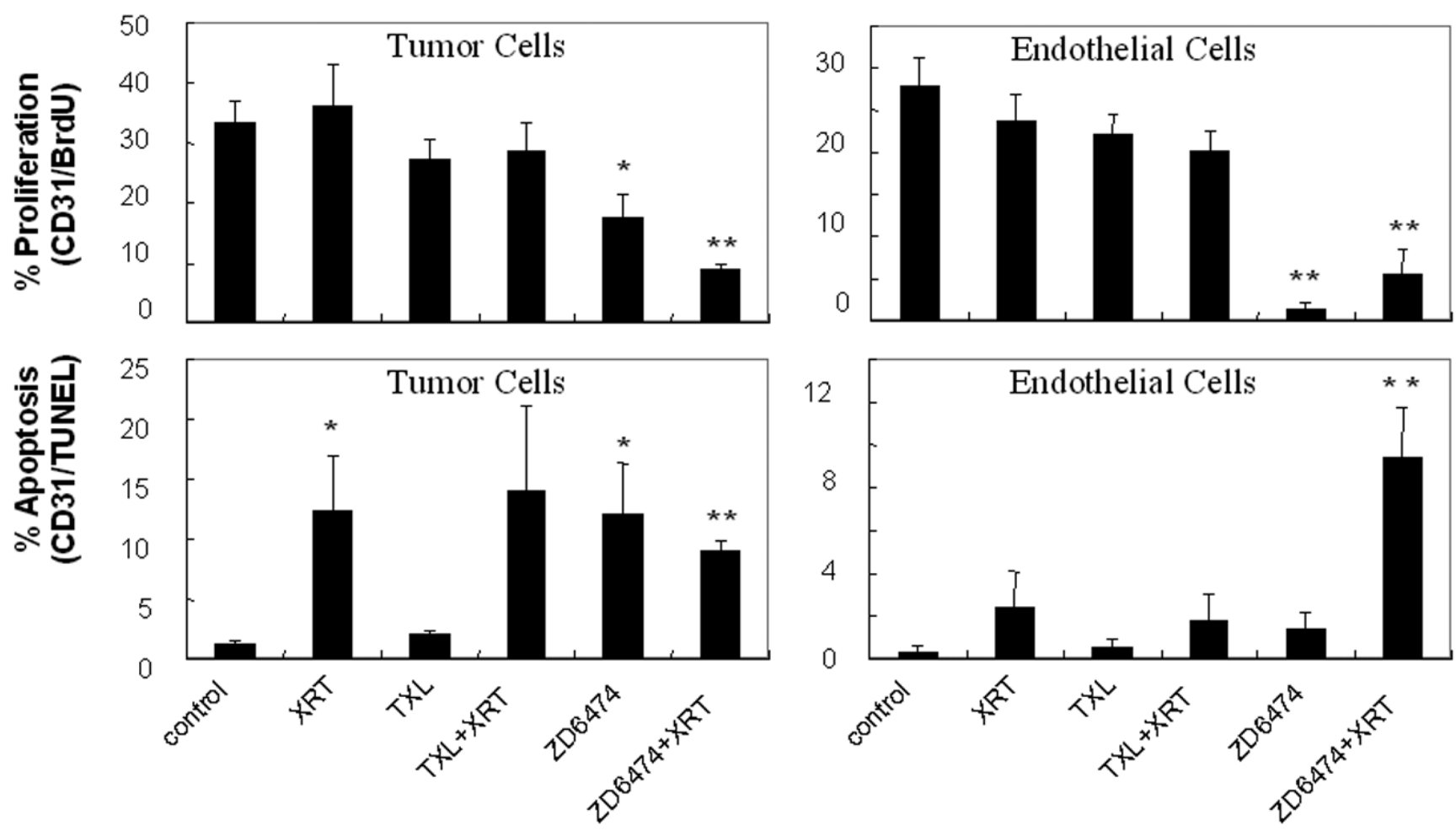

Figure 4.

Microvessel density (MVD) and tumor and endothelial cell proliferation and apoptosis. A, Representative sections obtained from primary lung tumors stained with CD31 (brown staining, upper panels) or double stained with CD31 (endothelial cells, red fluorescence) and TUNEL (apoptosis, green fluorescence, middle panels) or BrdU (proliferation, green fluorescence, lower panels). Proliferating or apoptotic endothelial cells fluoresce yellow and proliferating or apoptotic tumor cells fluoresce green. MVD was quantified in 10 random $0.159-\mathrm{mm}^{2}$ fields at $\times 100$ magnification. $B$, Endothelial and tumor cell proliferation and apoptosis. BrdU- or TUNEL-positive endothelial cells were counted in 10 random 0.039$\mathrm{mm}^{2}$ fields at $\times 200$ magnification. Data was obtained from tumor tissues from 4 or more mice in each treatment group and are plotted as means \pm standard error for two independent experiments. $* \mathrm{p}<0.05, * * \mathrm{p}<0.01$ versus control. 
Figure 5A
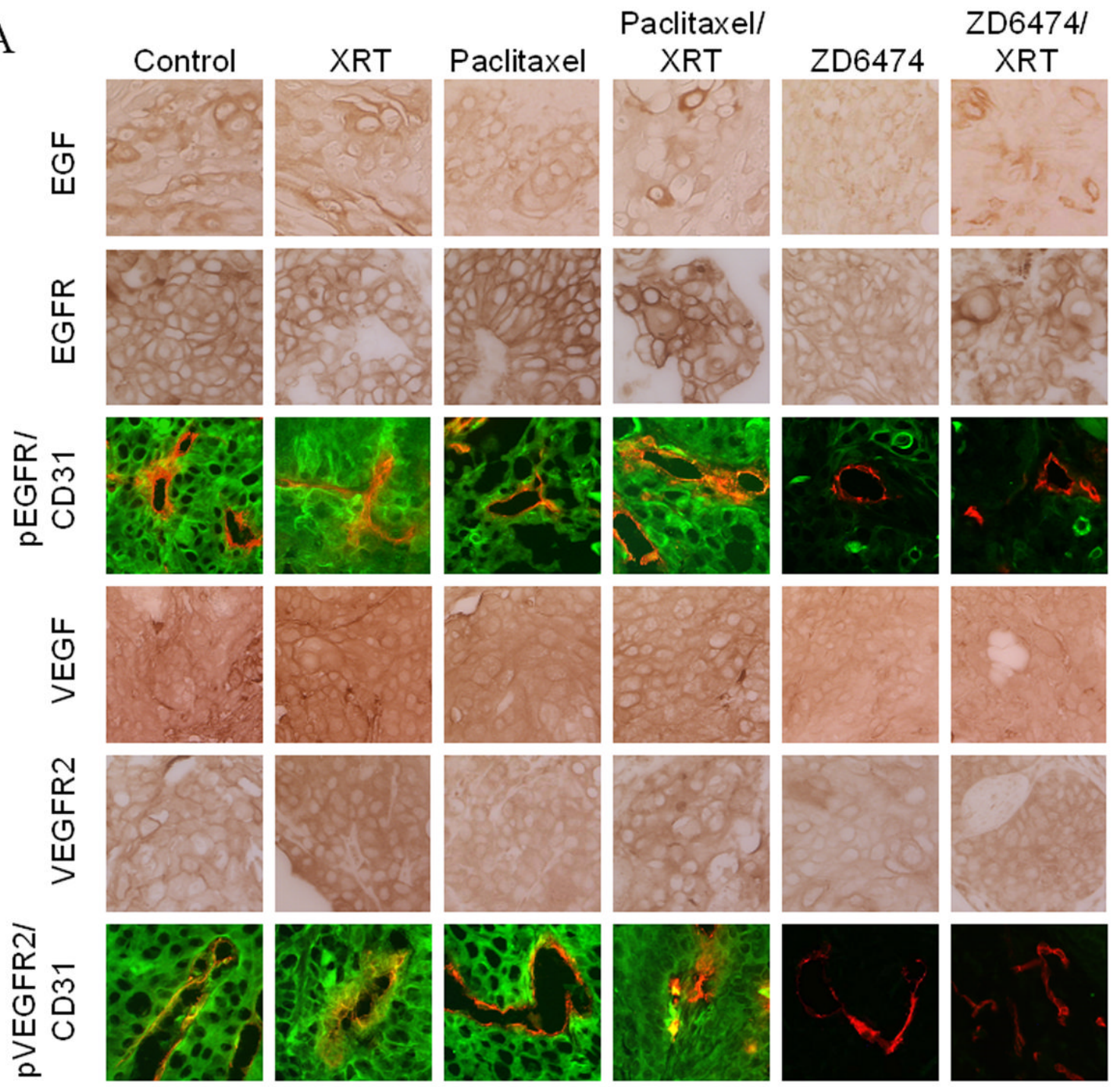


\section{Figure 5B}

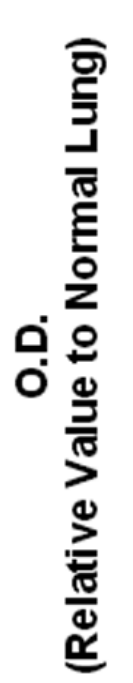

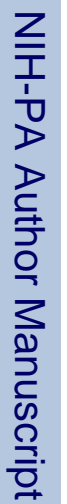

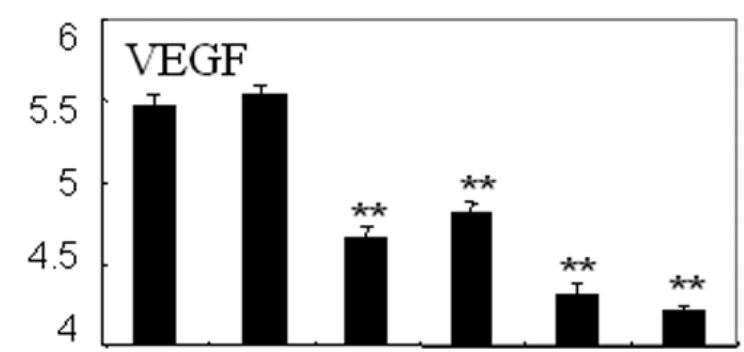

1.5

EGF
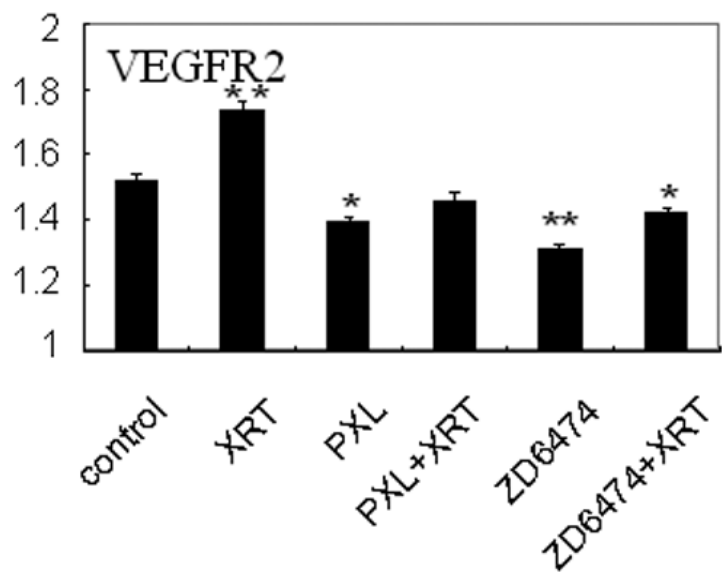
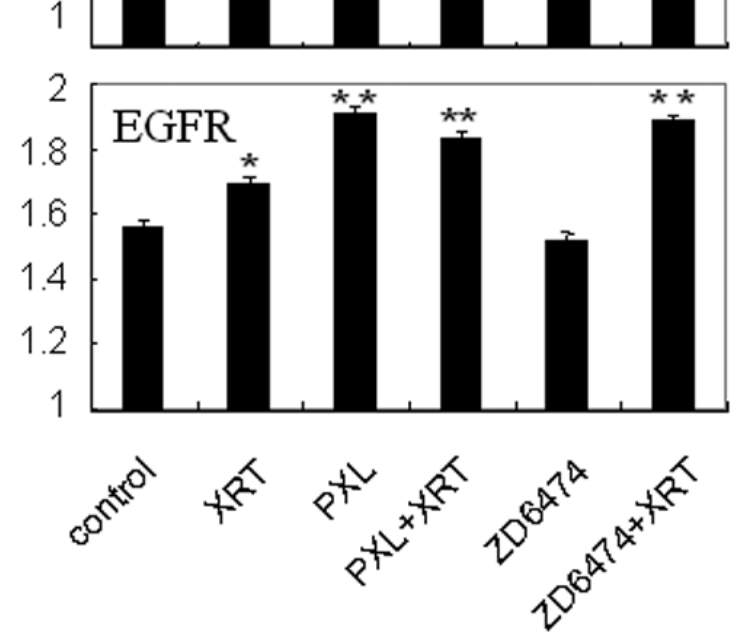

Figure 5C

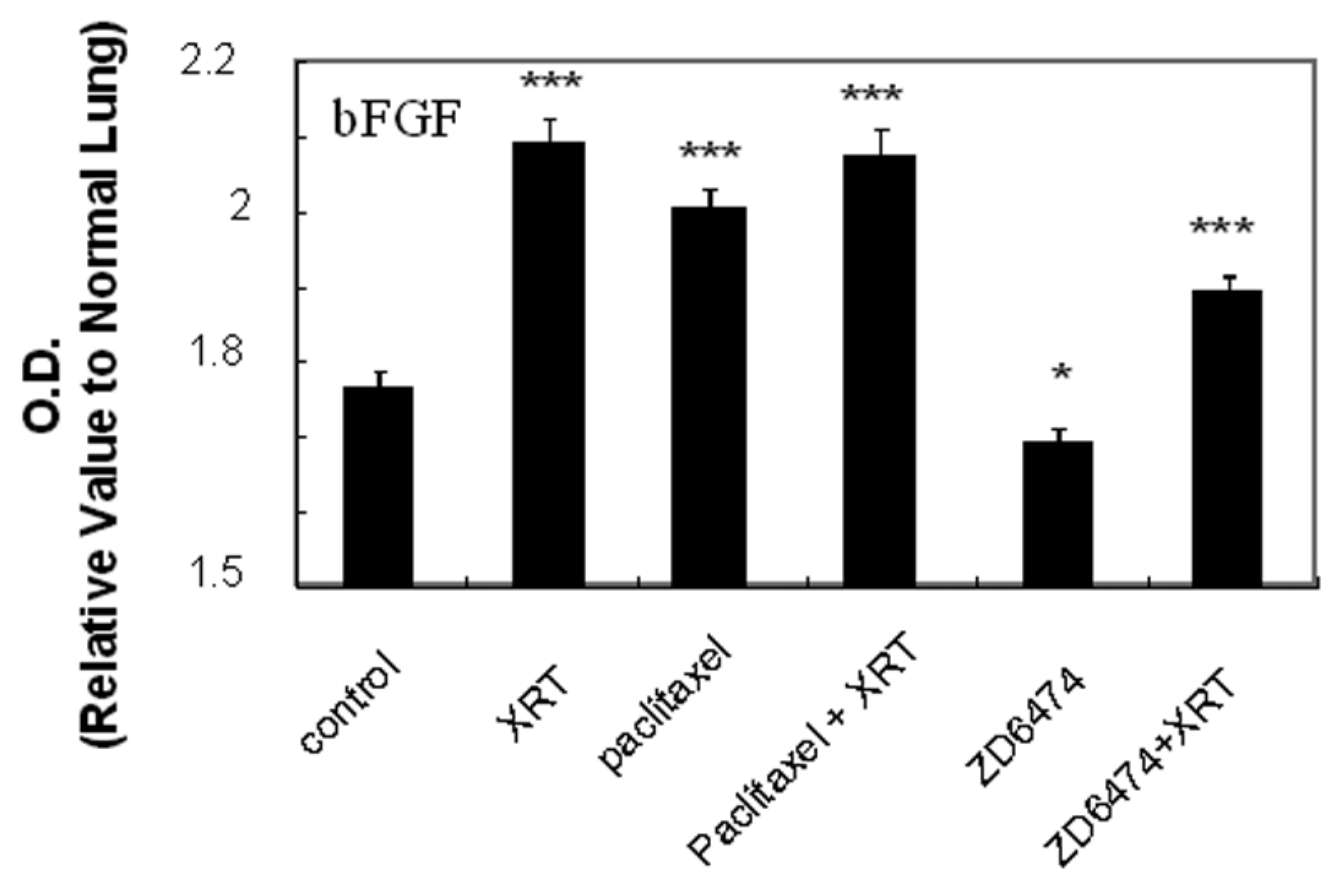

Int J Radiat Oncol Biol Phys. Author manuscript; available in PMC 2007 December 24 
Figure 5.

Immunohistochemical analyses of EGF, EGFR, pEGFR, VEGF, VEGFR2, pVEGFR2, and bFGF. A, Representative sections from primary lung tumors from each treatment group stained with antibodies against EGF, EGFR, VEGF, or VEGFR (brown staining) or double stained with CD31 (endothelial cells, red fluorescence) and pEGFR (green fluorescence, $3^{\text {rd }}$ row) or pVEGFR2 (green fluorescence, bottom row). Endothelial cells with activated EGFR or VEGFR2 fluoresce yellow. $B$, Lung tumor expression of VEGF, VEGFR2, EGF, or EGFR. $C$, Lung tumor expression of bFGF. Data was obtained from tumor tissues from 4 or more mice from each treatment group and are plotted as means \pm standard error for two independent experiments. ${ }^{*} \mathrm{p}<0.05, * * \mathrm{p}<0.01, * * * \mathrm{p}<0.001$ versus control. 